\title{
CARACTERIZAÇÃO, USO E LIMITAÇÕES DA GLICERINA NA ALIMENTAÇÃO DE SUÍNOS: REVISÃO
}

Guiomar Helena Verussa ${ }^{1}$ Anderson Corassa

Douglas dos Santos Pina Ana Paula Silva Ton ${ }^{1}$

Claudia Marie Komiyama ${ }^{1}$ Rafaeli Gonçalves Leite ${ }^{1}$

VERUSSA, G. H.; CORASSA, A.; PINA, D. dos S.; TON, A. P. S.; KOMIYAMA, C. M.; LEITE, R. G. Caracterização, uso e limitações da glicerina na alimentação de suínos: revisão. Arq. Ciênc. Vet. Zool. UNIPAR, Umuarama, v. 19, n. 3, p. 179-186, jul./set. 2016.

RESUMO: Glicerina é um líquido adocicado, higroscópico, inodoro, viscoso, energético, contendo variáveis níveis de glicerol, sendo utilizado como nutriente glicogênico ou lipogênico, dependendo da condição energética do animal. O glicerol ou 1,2,3-propanotriol é pertencente a função álcool, com três hidroxilas, de fórmula molecular $\mathrm{C}_{3} \mathrm{H}_{8} \mathrm{O}_{3}$. Em suínos, altos níveis de inclusão de glicerina podem proporcionar baixo conteúdo energético, pois o sistema enzimático da glicerol quinase torna-se saturado na conversão do glicerol para glicerol-3-fosfato, sendo o excesso excretado pela urina. A matéria-prima é um dos fatores que mais influenciam na composição da glicerina, podendo ser produzida a partir de óleo de soja, sebo bovino, gordura amarela e gordura de aves. Os componentes com maior participação na composição são glicerol, água e lipídios, contudo as limitações de seu uso na alimentação animal estão ligadas aos níveis residuais de sódio, potássio, metanol e umidade. Os níveis de glicerina bruta mais indicados para a viabilidade técnica e econômica estão em torno de 10\%, sendo que acima de $15 \%$ compromete o desempenho e a viabilidade econômica. Por possuir características favoráveis e teores de energia em torno de $3.579 \mathrm{kcal} / \mathrm{kg}$ de energia metabolizável, a glicerina pode ser utilizada como ingrediente energético em rações para suínos.

PALAVRAS-CHAVE: Biocombustível. Coproduto. Glicerol. Metabolismo. Viabilidade.

\section{CHARACTERIZATION, USE AND LIMITATIONS OF GLYCERIN IN PIG FEED: A REVIEW}

\begin{abstract}
Glycerin is a sweet, hygroscopic, odorless, viscous, energetic liquid containing variable glycerol levels being used as glycogen or lipogenic nutrient, depending on the energy condition of the animal. Glycerol, or 1,2,3-propanetriol, belongs to the alcohol group, with three hydroxyls, and the molecular formula of $\mathrm{C}_{3} \mathrm{H}_{8} \mathrm{O}_{3}$. In pigs, the inclusion of high levels of glycerin can provide low energy content, since the enzyme system in glycerol kinase becomes saturated in the conversion of glycerol to glycerol-3-phosphate, with the excess being excreted in the urine. The feedstock is one of the factors that most influence the composition of glycerin, which may be produced from soybean oil, beef tallow, yellow grease, and poultry fat. The components with the highest involvement in the composition are glycerol, water and lipids, however, the limitations of use in animal feed are connected to residual levels of sodium, potassium, methanol and humidity. Crude glycerin levels better suited to the technical and economic viability are at approximately $10 \%$, while compromising the performance and economic viability if above 15\%. Since it has favorable characteristics and energy levels around $3.579 \mathrm{kcal} / \mathrm{kg}$ of metabolizable energy, glycerin can be used as an energy ingredient in pig feed.
\end{abstract}

KEYWORDS: Biofuel. Co-product. Glycerol. Metabolism. Viability.

\section{CARACTERIZACIÓN, USO Y LIMITACIONES DE GLICERINA EN ALIMENTACIÓN DE CERDOS: REVISIÓN}

RESUMEN: La glicerina es un líquido dulce, higroscópico, inodoro, viscoso, energético, que contiene niveles de glycerol variables, que se utililiza como nutriente glicogénico o lipogénico, dependiendo de la condición de energía del animal. El glicerol o 1, 2, 3- propanotriol, es perteneciente a función alcohol, con tres hidroxilas, de formula molecular $\mathrm{C}_{3} \mathrm{H}_{8} \mathrm{O}_{3}$ En cerdos, los altos niveles de inclusión de glicerina pueden proporcionar un bajo contenido energético, pues el sistema enzimático de glicerol quinase se hace saturado en la conversión de glicerol en glicerol-3-fosfato, siendo el exceso excretado por la orina. La materia prima es uno de los factores que más influyen en la composición de la glicerina, pudiendo ser producida a partir del aceite de soja, sebo de ganado, grasa amarilla y grasa de aves. Los componentes con mayor participación en la composición son glicerol, agua y lepidios, sin embargo, las limitaciones de su uso en la alimentación animal están conectadas a niveles residuales de sodio, potasio, metanol y humedad. Los niveles de glicerina cruda más adecuados para la viabilidad técnica y económica están alrededor de 10\%, siendo que más de 15\% compromete el rendimiento y la viabilidad económica. Por tener características favorables y niveles de energía alrededor de $3579 \mathrm{kcal} / \mathrm{kg}$ de energía metabolizable, la glicerina puede ser utilizada como ingrediente de energía en alimentación de cerdos.

PALABRAS CLAVE: Biocombustible. Coproducto. Glicerol. Metabolismo. Viabilidad.

DOI: https://doi.org/10.25110/arqvet.v19i3.2016.6093

'Programa de Pós-Graduação em Zootecnia da Universidade Federal do Mato Grosso (UFMT). Autor para correspondência: rafaelizootecnia@hotmail.com 


\section{Introdução}

A suinocultura brasileira vem apresentando significativo aumento na produção de carne, passando de 2.998 mil toneladas em 2007 para 3.428 mil toneladas em 2013. Esse aumento se deve a fatores como aumento do consumo da carne suína, que passou de $13 \mathrm{~kg}$ em 2007 para cerca de 14,6 kg "per capita", no ano de 2014, e à disponibilidade de matéria prima como soja e milho considerados principais ingredientes utilizados na alimentação desses animais (ABPA, 2015). O milho é considerado a principal fonte de energia na alimentação animal, tendo uma participação em torno de 70\% na composição das rações (MELO, 2012). A estimativa de produção de grãos brasileira na safra 2015/16 é de 186,4 milhões de toneladas (CONAB, 2016). Mesmo com essa grande produção de grãos, onde se inclui o milho, esse cereal tem seu valor agregado devido sua ampla escala de utilização, contudo com grande oscilação de preço durante o ano devido à oferta e demanda do produto.

Com o intuito de se diminuir o impacto dessas variações de preços sobre os lucros finais na suinocultura, profissionais e produtores vem buscando alternativas nutricionais a fim de se alcançar uma possível substituição do milho por alimentos alternativos de forma a manter a viabilidade econômica e a qualidade nutricional da ração para o bom desempenho animal. Dentre estas alternativas, a utilização da glicerina, um coproduto da produção do biodiesel, é uma opção que vem sendo empregada na alimentação de suínos devido ao seu teor de energia.

O Brasil tem cerca de $44,1 \%$ da sua matriz energética advinda de fontes renováveis, com uma produção de biodiesel de quase 3,4 milhões de metros cúbicos em 2014, sendo que essa produção foi inferior à capacidade brasileira de produção de 7,7 milhões de metros cúbicos (ANP, 2015), gerando uma situação de aumento dos coprodutos oriundos desse processo químico o qual se inclui a glicerina, trazendo a preocupação de se buscar uma finalidade para esses excedentes. Nesse sentido, a glicerina é aparentemente o único coproduto associado à cadeia produtiva do biodiesel que tem um valor energético capaz de contribuir favoravelmente em dietas para suínos.

Além de possuir um alto teor de energia, com cerca de $3.579 \mathrm{kcal} / \mathrm{kg}$ de energia metabolizável, que se assemelha ao do milho com cerca de $3.340 \mathrm{kcal} / \mathrm{kg}$ (ROSTAGNO et al., 2011), a glicerina é considerada palatável para os animais por ser um líquido de sabor adocicado, podendo ser utilizada pelos suínos como qualquer nutriente glicogênico ou lipogênico (JAGGER, 2008). Logo, aprofundar as informações sobre a produção da glicerina, sua composição, metabolismo, características nutricionais, restrições de uso e desempenho dos animais torna-se importante para o correto uso deste ingrediente na alimentação de suínos, sendo esse o objetivo desse trabalho.

\section{Desenvolvimento}

\section{Produção do biodiesel}

O biocombustível é uma fonte de energia renovável derivado de produtos agrícolas como a cana de açúcar, plantas oleaginosas e outras fontes de matéria orgânica, cujo objetivo principal da produção está na tentativa de reduzir a dependência dos combustíveis derivados do petróleo. Dentre os biocombustíveis destacam-se o etanol, o metanol, o biogás, o carvão vegetal e o biodiesel (APOLINÁRIO; PEREIRA; FERREIRA, 2012).

O biodiesel denominado como um mono-alquil éster de ácidos graxos, é visto como uma das formas mais eficientes de diversificação da matriz energética, pois contribui para a conservação do meio ambiente, por meio da redução da emissão de gases de efeito estufa. Na comparação com o diesel de petróleo, o biodiesel tem significativas vantagens ambientais na qual sua queima pode emitir, em média, $48 \%$ menos monóxido de carbono, $47 \%$ menos material particulado e $67 \%$ menos hidrocarbonetos (ANP, 2015).

A produção e comercialização nacional do biodiesel possuem grande potencial devido à grande disponibilidade de matéria-prima advinda da diversidade de culturas oleaginosas disponíveis para sua produção. $\mathrm{O}$ biodiesel pode ser obtido de vegetais como óleo de soja, girassol, amendoim palma, algodão dentre outros, e de gorduras animais como sebo de boi, gordura de frango e de suínos e resíduos industriais e domésticos. Segundo a Agencia Nacional de Petróleo (ANP, 2015), o perfil de matérias-primas utilizadas para produção de biodiesel em 2013 teve como principais fontes o óleo de soja com cerca de $69 \%$ e o sebo bovino com cerca de $26 \%$.

Segundo estudo de Oliveira et al. (2013), que analisaram a produção de biodiesel de diferentes fontes de usinas localizadas nas principais regiões produtoras do Brasil, do total de biodiesel produzido pelas 16 usinas avaliadas, 33,2\% foram de usinas que trabalham exclusivamente com óleo de soja, 36,8\% das que trabalham com óleo de soja e sebo e $9,1 \%$ das que trabalham com óleos de soja e algodão.

No sentido de alavancar o uso dessas fontes renováveis de energia, em janeiro de 2010 entrou em vigor uma determinação do Programa Nacional de Produção e Uso de Biodiesel (PNPB) por meio da resolução $n^{\circ} 06 / 2009$, a qual determinou que o óleo diesel comercializado em todo o Brasil deveria conter $5 \%$ de biodiesel em sua composição, o que foi considerado um aumento significativo em relação aos $2 \%$ de inclusão utilizados até então (ANP, 2015). O cumprimento integral dessa resolução pode gerar um aumento na produção do biodiesel, que por sua vez leva à uma situação de aumento também dos coprodutos oriundos desse processo químico, como farelos, tortas e principalmente a glicerina, que segundo Bowker et al. (2008), para cada tonelada de biodiesel obtido são gerados $100 \mathrm{~kg}$ da mesma, trazendo a preocupação de se buscar uma finalidade para esses excedentes.

A glicerina é obtida como coproduto da produção do biodiesel que se dá pelas seguintes etapas: preparação da matéria-prima, reação de transesterificação, separação de fases, recuperação e desidratação do álcool e purificação da glicerina e do biodiesel (APOLINÁRIO; PEREIRA; FERREIRA, 2012). A preparação da matéria-prima é importante para criar condições que favoreçam a reação de transesterificação, obtendo a máxima taxa de conversão. A matéria-prima utilizada deve possuir o mínimo de umidade e de acidez, o que é possível através de um processo de neutralização com uma solução alcalina seguida de uma operação de secagem (LEONETI et al., 2012).

A reação de transesterificação ocorre com a mistu- 
ra de uma fonte de óleo com um álcool e um catalizador, possibilitando a ruptura dos triglicerídeos em moléculas menores de metil ésteres de ácidos graxos. Para esta reação, o catalizador normalmente utilizado é o hidróxido de sódio ou potássio enquanto que os alcoóis mais adequados são: etanol, propanol, butanol, álcool amílico e metanol, sendo este último utilizado com mais frequência por possuir baixo custo e algumas vantagens físicas e químicas como: polariedade, álcool de cadeia mais curta, reação rápida com triglicerídeos e dissolução fácil com o catalisador básico (APOLINÁRIO; PEREIRA; FERREIRA, 2012).

Dentre os catalisadores empregados nessa reação, o uso de biocatalizadores como enzimas lipases, bactérias, leveduras e fungos têm sido estudados devido à ausência de formação de sabão e simplicidade do processo de purificação dos produtos e coprodutos. No entanto, estes biocatalisadores não têm sido empregados industrialmente devido ao grande tempo de conversão e seu alto custo, sendo os catalisadores químicos os mais empregados (KOJIMA et al., 2004).

A etapa de separação de fases, após a reação de transesterificação, converte a porção oleosa em ésteres originando o biodiesel e uma mistura final chamada de glicerina bruta, impregnada de resíduos de álcool, água, sódio, e outras impurezas. A glicerina bruta é submetida a um processo de hidrólise ácida para remoção dos sabões. Essa glicerina, após a hidrólise, é denominada de glicerina loira ou semipurificada. Após a remoção dos sabões, a glicerina vai para o processo de evaporação, para eliminação dos constituintes voláteis. Parte do álcool não reagido no processo de transesterificação passa pelo processo de recuperação e desidratação. O excesso residual de álcool, após os processos de recuperação, contém quantidades significativas de água, necessitando de uma separação feita normalmente por destilação (RIVALDI et al., 2008). As etapas da produção do biodiesel são demonstradas na Figura 1.

Figura 1: Etapas da produção do biodiesel.

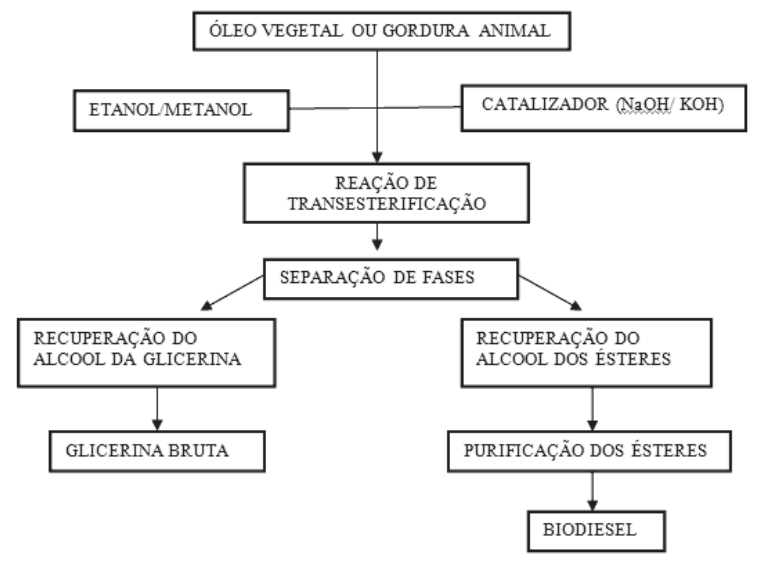

Fonte: Adaptado Rivaldi et al. (2008).

A glicerina possui três graus de pureza devido às variações que ocorrem nos teores de resíduos de água, ácido graxo, metanol, fósforo, sódio e principalmente do glicerol pelo qual ocorre sua classificação em baixa pureza com até $70 \%$ de glicerol, média pureza com 70 a $90 \%$ de glicerol e alta pureza com teores de glicerol acima de 90\% (ARRUDA et al., 2007; APOLINÁRIO; PEREIRA; FERREIRA, 2012).

A glicerina semipurificada passa por processos de purificação, o que reduz os teores de ácidos graxos, metanol e também os resíduos de catalizadores (sódio ou potássio) em sua composição, o que torna a glicerina semipurificada um ingrediente de melhor qualidade para uso na alimentação animal (GONÇALVES et al., 2014).

Carvalho et al. (2013), relataram que a glicerina pode ser destinada à alimentação animal na forma bruta com alto conteúdo de ácidos graxos ou na forma semipurificada, conhecida como "Loira” com menor conteúdo de ácidos graxos, sendo essa segunda largamente utilizada na fabricação de cosméticos e medicamentos.

\section{Características e composição química da glicerina}

De acordo com Jagger, (2008), a glicerina é um líquido de sabor adocicado, altamente energético e que pode ser utilizada pelos suínos como nutriente glicogênico ou lipogênico, dependendo da condição energética do animal.

A palavra glicerina pode ser empregada como sinônimo do glicerol. Porém, na prática, a palavra glicerina é empregada para fazer referência de que não se trata de uma substância pura e se aplica aos produtos comerciais que contenham até $95 \%$ de glicerol na sua composição. Enquanto o glicerol é considerado o produto puro (GONÇALVES et al., 2014).

O glicerol, quimicamente conhecido como 1,2,3-Propanotriol, é um composto orgânico pertencente a função álcool, com três hidroxilas, de fórmula molecular $\mathrm{C}_{3} \mathrm{H}_{8} \mathrm{O}_{3}$. É líquido à temperatura ambiente, higroscópico, inodoro, viscoso e de sabor adocicado (ARRUDA et al., 2007).

O glicerol está presente naturalmente nos organismos vegetais e animais. No entanto, é difícil ser encontrado na forma "livre" nesses organismos, pois geralmente se encontra sob a forma de triacilglicerol, associado a três ácidos graxos de cadeia longa como, por exemplo, os ácidos oleico, palmítico e esteárico, sendo dessa forma, armazenado nos animais e vegetais (ARRUDA et al., 2007).

A matéria prima é um dos fatores que mais influenciam na composição da glicerina, entretanto, quando se trabalha em escala industrial, alguns resultados indicam que a eficiência das técnicas empregadas na produção do biodiesel parece ter uma maior influência na composição final da glicerina (THOMPSON; HE, 2006; ARRUDA et al., 2007). Nesse sentido, Kerr et al. (2009), consideram que a composição química e o teor de glicerol contido na glicerina dependem do tipo de matéria prima utilizada (óleo vegetal ou gordura animal) e da eficiência do processo de produção do biodiesel, sendo que quanto maior for o valor de energia bruta juntamente com um menor teor de glicerol menos eficiente foi o processo de transformação, o qual gera como produto final a glicerina com maior teor de triglicerídeos intactos o que pode interferir no valor de energia bruta.

A partir do pressuposto de que as diferenças na composição de glicerina podem afetar a energia bruta e, consequentemente, a energia metabolizável, Kerr et al. (2009), ajustaram modelos de regressão para caracterizar a relação da composição da glicerina com o valor de energia bruta e metabolizável: EB $(\mathrm{kcal} / \mathrm{kg})=-236+(46,08 \times \%$ de glicerol $)$ $+(61,78 \% \times \%$ de metanol $)+(103,62 \times \%$ de ácidos graxos $)$, $\left(\mathrm{R}^{2}=0,99, \mathrm{P}<0,01\right)$ e $\mathrm{EM} \mathrm{kcal} / \mathrm{kg}=(37,09 \times \%$ de glicerol $)$ $+(97,15 \% \times \%$ ácidos graxos $),\left(\mathrm{R}^{2}=0,41 ; \mathrm{P}<0,01\right)$. Os re- 
sultados obtidos com a regressão foram similares aos valores reais, sugerindo que a estimativa da energia bruta e metabolizável da glicerina a partir de sua composição foi precisa.

Segundo estudo de Oliveira et al. (2013), que analisaram a composição de glicerinas oriundas de diferentes fontes de usinas nas principais regiões produtoras do Brasil, os componentes com maior participação na composição da glicerina são glicerol, água e lipídios.

A maioria dos trabalhos que avaliam o valor nutricional da glicerina para suínos utilizam glicerinas provenientes de óleo de soja, devido sua maior escala de utilização para a produção de biodiesel. Nesse sentido, Schieck et al. (2009), avaliaram a composição de glicerina de óleo de soja e encontraram teor de glicerol de $82,3 \%$, enquanto Lammers et al. (2008a), encontraram $86,95 \%$ com um teor de energia bruta de $3.625 \mathrm{kcal} / \mathrm{kg}$ e Rostagno et al. (2011), relatam 3.579 $\mathrm{kcal} / \mathrm{kg}$ de energia metabolizável da glicerina com $87 \%$ de glicerol.

Trabalhando com glicerinas provenientes de diferentes matérias primas (óleo de soja e mista com $80 \%$ de gordura animal e $20 \%$ de óleo de soja), Carvalho et al. (2013), encontraram diferentes composições das mesmas, representadas principalmente pelos teores de energia bruta, glicerol, metanol, sódio, potássio e ácidos graxos. Em relação à glicerina de óleo de soja foram encontrados os valores de $5.247 \mathrm{kcal} / \mathrm{kg}, 55,95 \%, 10,96 \%$ e $1,62 \%, 0,06 \%$ e $23,3 \%$ para teores de energia bruta, glicerol, metanol, sódio, potássio e ácidos graxos respectivamente, enquanto para a glicerina mista os valores foram $5.242 \mathrm{kcal} / \mathrm{kg}, 55,45 \%, 5,05 \%$, $1,99 \%, 0,174 \%$ e $21,5 \%$, respectivamente. De maneira similar, Gonçalves et al. (2014), também trabalharam com glicerina de óleo de soja e mista, porém encontraram maiores teores de glicerol, com 74,94 e 68,66\% respectivamente, e menores teores de energia bruta de ambas as glicerinas com $3.760 \mathrm{kcal} / \mathrm{kg}$ para glicerina de óleo de soja e $3.217 \mathrm{kcal} / \mathrm{kg}$ para glicerina mista.

Kerr et al. (2009), analisaram a composição química de glicerinas provenientes do óleo de soja, sebo bovino, gordura amarela e gordura de aves, encontrando uma variação já esperada, segundo os autores, principalmente nos teores de glicerol, metanol e ácidos graxos. Os teores de glicerol das glicerinas de óleo de soja foram maiores que das glicerinas obtidas de gordura animal, ficando numa média de $83,9 \%$, enquanto que a glicerina obtida a partir do sebo obteve um valor de $73,34 \%$ e de gordura de aves $51,54 \%$. Os teores de ácidos graxos foram inversamente proporcionais aos teores de glicerol, onde glicerinas com alto teor de glicerol obtiveram valores de ácidos graxos reduzidos. $\mathrm{O}$ teor de metanol foi relativamente pequeno em todas as amostras exceto para amostra da glicerina oriunda da gordura de aves que obteve $14,99 \%$ de metanol, valor que pode ser considerado preocupante devido possibilidade de intoxicação dos animais alimentados com essa glicerina.

\section{Restrições do uso da glicerina na nutrição animal}

O uso da glicerina em produtos alimentícios é assegurado pela resolução n³86 de 5 de agosto de 1999 . Em maio de 2010, o Ministério da Agricultura, Pecuária e Abastecimento (MAPA) autorizou o uso da glicerina bruta como insumo para alimentação animal e estabeleceu um pa- drão mínimo de qualidade, como: glicerol (mínimo de 800 $\mathrm{g} / \mathrm{kg}$ ), umidade (máximo $130 \mathrm{~g} / \mathrm{kg}$ ), metanol (máximo 159 $\mathrm{mg} / \mathrm{kg}$ ), sódio e matéria mineral sendo os valores garantidos pelo fabricante $\mathrm{g} / \mathrm{kg}$, podendo variar pelo processo produtivo (BRASIL, 2010).

De acordo com o Departamento de Fiscalização dos Insumos Pecuários do MAPA, existem algumas limitações para o uso da glicerina na ração de ordem tecnológica, zootécnica e econômica, pois para se tornar viável, o preço da glicerina precisa ser competitivo em relação ao preço da soja e do milho, seu principal concorrente (BRASIL, 2010).

Melo (2012), afirma que os níveis de glicerina bruta mais indicados para melhorar a viabilidade técnica e econômica estão em torno de $10 \%$, sendo que o uso acima de $15 \%$ compromete negativamente o desempenho e a viabilidade econômica. Gallego et al. (2014), em seus estudos utilizando glicerina semipurificada, mostraram que não houve alteração do custo da ração por quilograma de peso vivo ganho com a inclusão de até $14 \%$ de glicerina semipurificada. Porém, acima disso pode ocorrer aumento em até $2,9 \%$ no custo das rações, dependendo da relação de preços dos ingredientes.

Uma análise econômica feita por Carvalho et al. (2013), mostrou redução linear do custo de ração para suínos na fase inicial, com o aumento dos níveis de inclusão de glicerina bruta, tanto de origem vegetal quanto mista com aproximadamente $80 \%$ de gordura animal $+20 \%$ de óleo de soja. Os autores afirmaram que essa resposta é reflexo da relação de preços existentes entre os ingredientes utilizados, principalmente o milho, uma vez que à medida que se adiciona a glicerina, ocorre redução do milho, que tem o custo mais elevado. Assim, os autores sugerem a inclusão de até 12\% de glicerina bruta vegetal.

As limitações zootécnicas estão relacionadas aos fatores de qualidade da produção da glicerina que necessitam de atenção especial devido às preocupações sobre os níveis residuais, principalmente de sódio, potássio, metanol e umidade da glicerina para sua utilização na alimentação animal (BRASIL, 2010).

O excesso de sódio na dieta de suínos pode aumentar a osmolalidade da digesta, o fluxo de água da mucosa intestinal para o lúmen e aumentar a incidência de fezes pastosas ou líquidas. Dessa forma, níveis de sódio acima da exigência podem interferir negativamente no balanço intestinal da água e prejudicar o desempenho dos animais (PATIENCE; ZIJLSTRA, 2001). O potássio é menos tolerado que o sódio sob desafios agudos. Os principais efeitos do excesso de potássio no organismo animal são o distúrbio no equilíbrio ácido-básico, hipocalcemia e a insuficiência cardíaca (ARAUJO et al., 2010).

No metabolismo do metanol no organismo animal são formados dióxido de carbono e água juntamente com os intermediários formaldeído e o formato. O metanol ingerido é oxidado no fígado a formaldeído que por sua vez é oxidado a ácido fórmico que é uma substância tóxica. A intoxicação por metanol em animais pode ser identificada pela excreção de ácido fórmico na urina. Em quantidades elevadas, o ácido fórmico pode causar cegueira pela destruição do nervo óptico, sendo relatadas também a ocorrência de depressão do sistema nervoso central, vômito, acidose metabólica e alteração motora (KEER et al., 2009, MENTEN; ZAVARIZE; SILVA, 2010). 
Lammers et al. (2008b) trabalhando com glicerina de origem vegetal com cerca de $0,32 \%$ de resíduo de metanol verificaram que essa concentração de metanol nas dietas não afetou negativamente o desempenho dos suínos nem demonstraram quaisquer sinais clínicos de toxicidade do metanol ou lesões histológicas em orgãos considerados alvos farmacológicos para a toxicidade do metanol como rins e fígado.

Hansen et al. (2009), afirmaram que o uso da glicerina pode ser influenciado tanto pelo nível de sua inclusão na dieta quanto pelo tipo de glicerina utilizada, devendo ser levado em consideração, no momento da formulação das dietas, a variação de parâmetros de sua composição e a quantidade de minerais.

\section{Metabolismo do glicerol}

O glicerol é um componente do metabolismo normal dos animais, sendo encontrado na circulação sanguinea e nas células, podendo ser derivado da lipólise no tecido adiposo, da hidrólise dos triglicerídeos das lipoproteínas do sangue e da gordura dietética (LIN, 1977; MENTEN; ZAVARIZE; SILVA, 2010).

Em monogástricos, o glicerol proveniente da dieta pode ser absorvido no estômago e no intestino, sendo este segundo o local de mais rápida absorção por difusão passiva nos enterócitos sem necessidade de formação de micelas como ocorre com os ácidos graxos. Uma vez absorvido, o glicerol é transferido para o fígado e outros tecidos para ser metabolizado. Para sua metabolização, o glicerol deve ser convertido em glicerol-3-fosfato, sofrendo ação da enzima glicerolquinase presente no fígado, rins e músculo e da glicerol-3-fosfato desidrogenase no tecido adiposo (LIN, 1977; SILVA, 2010).

Em suínos, pode ocorrer uma limitação na ativação de enzimas para utilização de glicerol, sendo que altos níveis de inclusão de glicerina na alimentação podem proporcionar baixo conteúdo energético, pois o sistema enzimático da glicerolquinase torna-se saturado na conversão do glicerol para glicerol-3-fosfato, sendo o glicerol em excesso excretado pela urina (DOPPENBERG; VAN DER AAR, 2007).

O destino metabólico do glicerol é dependente do tecido e do estado nutricional do animal (Figura 2). Em situação de balanço energético positivo, o glicerol atua como precursor da síntese de triglicerídeos, enquanto em situação de déficit de energia é utilizado para o fornecimento de esqueleto carbônico para a gliconeogênese ou oxidação para a produção de energia por meio da glicólise e do ciclo de Krebs (LIN, 1977).

Segundo Cerrate et al. (2006), o glicerol pode também ter efeitos sobre a retenção de aminoácidos ou nitrogênio, favorecendo a deposição de proteína corporal por meio da inibição da atividade das enzimas fosfoenolpiruvato carboxiquinase e glutamato desidrogenase que participam do metabolismo proteico.
Figura 2: Metabolismo do glicerol no organismo animal.

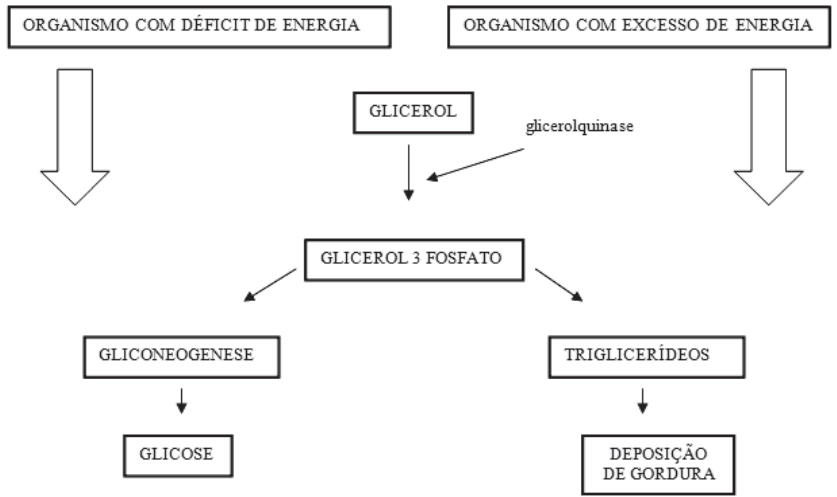

Fonte: Silva, 2010.

De acordo com Gallego et al. (2014), o metabolismo do glicerol pode ser convertido em glicose por meio da gliconeogênese, ou oxidado, produzindo energia através da glicólise. Nesse sentido, os autores avaliaram os teores de glicose, colesterol e triglicerídeos plasmáticos em suínos alimentados com diferentes níveis de inclusão de glicerina semipurificada neutralizada o qual não encontrou nenhum efeito significativo. Em contrapartida, os resultados de Huepa, (2013), mostraram que a inclusão de glicerina semipurificada na fase pré-inicial promoveu efeito linear crescente para o teor de triglicerídeos de acordo com o aumento do nível de inclusão, enquanto que não foram observados efeitos sobre a glicose. $\mathrm{O}$ autor explica que o aumento de triglicerídeos no sangue está associado ao aumento da concentração de glicerol e ácidos graxos livres, sendo que, parte destes últimos são conduzidos da corrente sanguínea até os tecidos para produção de energia.

\section{Glicerina na alimentação de suínos}

A fase inicial deve ser vista com muito cuidado, pois os leitões desmamados normalmente estão em estado de balanço energético negativo, devido ao apetite limitado em função da mudança alimentar do leite para a ração. Nesse sentido o uso de ingredientes de alta qualidade são alternativas utilizadas para melhorar a palatabilidade e digestibilidade da ração, além de colaborar com o amadurecimento intestinal, o que é de suma importância para o devido desenvolvimento da capacidade digestiva do animal.

Segundo Rocha (2013), a fase da desmama é caracterizada por alterações ambientais e nutricionais que levam a baixa ingestão de alimento que por sua vez leva a alterações intestinais como encurtamento das vilosidades, aprofundamento das criptas e menor área disponível para absorção. $\mathrm{O}$ autor afirma que por ser uma fonte de energia prontamente disponível, a glicerina tem potencial para substituir partes dos cereais e óleos das rações, e também outros ingredientes utilizados nessa fase como o soro de leite e a lactose. Nesse sentido, seu estudo avaliando substituição de soro de leite e da lactose por glicerina para animais nessa fase, mostrou que não houve diferença nas medidas morfométricas intestinais avaliadas (altura, largura e superfície de vilosidades, e profundidade de criptas), e ainda concluiu que a glicerina pode ser utilizada como fonte alternativa em substituição ao soro de leite em pó nas dietas para leitões em até $18 \%$ sem alterar 
o desempenho, e em substituição á lactose em até 3\% promovendo um maior ganho de peso médio diário.

Christopher (2009), substituindo a lactose por glicerina na alimentação de leitões recém-desmamados, afirma que a glicerina pode ser adicionada nas dietas em níveis de até $5 \%$ sem prejudicar o desempenho dos animais. Van Heugten et al. (2008) forneceram rações suplementadas com glicerina e lactose a $10 \%$ cada para leitões na fase de creche, e verificaram aumento do peso corporal e melhoria na eficiência alimentar durante a primeira e segunda semana pós desmame.

Ao avaliar leitões recém-desmamados, Zijlstra et al. (2009), observaram que o valor de energia digestível para a glicerina semipurificada foi de $3.510 \mathrm{kcal} / \mathrm{kg}$, sendo que a inclusão de até $8 \%$ nas dietas beneficiou estes animais, que geralmente encontram-se em estado de deficiência de energia. Gallego et al. (2014), encontraram um valor de 3.298 $\mathrm{kcal} / \mathrm{kg}$ de energia digestível para glicerina semipurificada também para leitões na fase inicial, em um nível de até $14 \%$ sem alterar o desempenho.

Gonçalves et al. (2014), compararam a digestibilidade de glicerinas semipurificadas provenientes do óleo de soja e mista ( $80 \%$ gordura animal e $20 \%$ oleo de soja), o qual encontraram valores de energia digestivel para leitões de 3.793 e $3.220 \mathrm{kcal} / \mathrm{kg}$ para as fontes de origem vegetal e mista, respectivamente.

Lammers et al. (2008a), encontraram valores de energia digestível e metabolizável da glicerina bruta de 3.344 e $3.207 \mathrm{kcal} / \mathrm{kg}$, respectivamente, sendo que em seu experimento foi observado um declínio na estimativa de energia metabolizável de acordo com o aumento da inclusão de glicerina na ração para leitões em fase de creche.

Groesbeck et al. (2008), recomendam a inclusão de até $12 \%$ de glicerina para suínos em crescimento, pelo seu sabor adocicado, proporcionando melhora na palatabilidade da dieta e, consequentemente, o consumo de ração, além de atuar de maneira positiva no desempenho dos animais e melhorar as propriedades físicas de dietas peletizadas. Em contrapartida, Carvalho et al. (2013), afirmam que a adição de glicerina nas rações para suínos em crescimento não interferiu na sua palatabilidade, fato evidenciado pela falta de efeito sobre consumo de ração, ganho de peso e conversão alimentar.

Em estudos com animais em fase de crescimento e terminação, Lammers et al. (2008b), afirmaram que a inclusão de até $10 \%$ de glicerina semipurificada não afetou o desempenho e as características de carcaça. Resultados semelhantes foram encontrados por Berenchtein et al. (2010), que analisaram fornecimento de glicerina para animais em crescimento e terminação em níveis de até $9 \%$, os quais não influenciaram o desempenho, as características de carcaça nem a qualidade da carne dos animais. No mesmo sentido Gonçalves et al. (2014), chegaram a uma adição de até 16\% de glicerina semipurificada de origem vegetal e mista $(80 \%$ gordura animal $+20 \%$ óleo de soja) sem prejudicar o desempenho e a qualidade de carcaça.

Hansen et al. (2009), não encontraram diferenças no $\mathrm{pH}$, perda por gotejamento, perda por cozimento, cor e força de cisalhamento com inclusão de até $16 \%$ de glicerina. De maneira similar, Melo et al. (2014), relataram que o uso de até $20 \%$ de inclusão de glicerina em dietas para suínos em terminação não promove alterações que prejudiquem os aspectos físico-químico da carne, mostrando ser um ingrediente com grande potencial de uso na suinocultura. Com nível de inclusão de glicerina de 30\% Mendonza et al. (2010), também não encontraram efeito nas características de carcaça.

Contrário aos resultados da maioria dos estudos citados, no trabalho de Hanczakowska et al. (2010), os autores afirmam que as características de carcaça de suínos alimentados com $10 \%$ de glicerina foram ligeiramente melhor do que dos animais alimentados sem adição de glicerina, com as carcaças apresentando maior espessura de toucinho, juntamente com uma maior área de olho de lombo.

De acordo com Lammers et al. (2008b) a quantidade e o perfil dos ácidos graxos presentes na composição da glicerina tem efeito sobre o perfil de ácidos graxos da gordura da carcaça dos animais alimentados com a mesma. Os autores encontraram menores concentrações de ácido linoleico e linolênico na gordura de animais alimentados com $10 \%$ de glicerina proveniente do óleo de soja, enquanto as concentrações do ácido eicosapentanoico aumentaram. Apesar de não encontrarem diferença significativa no perfil de ácidos graxos da gordura, Kerr et al. (2011), relatam que houve um pequeno aumento na concentração de ácido oleico, acompanhado por uma pequena diminuição da concentração de ácido linoléico e ácido linolênico na gordura de animais alimentados com 10\% de glicerina de óleo de soja. Da mesma forma, Mourot et al. (1994) não relataram nenhuma diferença significativa nas características de carcaça, com nível de 5\% de glicerina obtida de óleo de canola, mas notou um aumento significativo da proporção de ácido oleico no toucinho e diminuição de ácidos linoleico e linolênico.

Schieck et al. (2009), realizaram uma avaliação sensorial do lombo de suínos alimentados com $8 \%$ de glicerina, e de acordo com os resultados, as características de suculência, maciez, intensidade de aroma e sabor não foram afetados, sendo a carne bem aceita pelos provadores.

\section{Considerações Finais}

Por possuir características favoráveis e teores de energia satisfatórios, a glicerina pode ser utilizada como ingrediente energético em rações nas fases inicial, crescimento e terminação, sem influenciar negativamente o desempenho, as características de carcaça e a qualidade da carne de suínos.

\section{Referências}

ABPA. Associação Brasileira de Proteína Animal. Relatório anual 2015. Disponível em: < http://abpa-br.com.br/files/ RelatorioAnual_UBABEF_2015_DIGITAL.pdf $>$ Acesso em: 14 set. $201 \overline{6}$.

\section{ANP. Agência Nacional do Petróleo, Gás Natural e} Biocombustíveis. Anuário estatístico brasileiro do petróleo, gás natural e biocombustíveis. Disponível em: $<$ http://www.anp.gov.br/?pg=82346\&m=\&t1=\&t2=\&t3=\&t 4=\&ar $=\& p s=\& 1473863274118>$ Acesso em: 14 set. 2016.

APOLINARIO, F. D. B.; PEREIRA, G. F.; FERREIRA, J. P. Biodiesel e alternativas para utilização da glicerina resultante do processo de produção de biodiesel. Bolsista 
de Valor: Revista de divulgação do Projeto Universidade Petrobras e IF Fluminense v. 2, n. 1, p. 141-146, 2012.

ARAUJO, W. A. G. et al. Potássio na nutrição animal. Revista Eletrônica Nutritime, v. 7, n. 4, p.1280-1291, 2010

ARRUDA, P. V.; RODRIGUES, R. C. L. B.; FELIPE, M. G. A. Glicerol: um subproduto com grande capacidade industrial e metabólica Revista Analytica, n. 26, 2007.

BERENCHTEIN, B. Utilização de glicerol na dieta de suínos em crescimento e terminação. Revista Brasileira de Zootecnia, v. 39, n. 7, p. 1491-1496, 2010.

BRASIL. Ministério da Agricultura, Pecuária e Abastecimento. Ministério da Agricultura autoriza novo uso da glicerina. 2010. Disponível em: $<$ http://www. sindiracoes.org.br/index.php?option=com_content\&task=vi ew\&id=972Itemid=1>. Acesso em: 15 Fev. 2014.

BOWKER, M.; DAVIES, P. R.; AL-MAZROAI, L. S. Photocatalytic reforming of glycerol over gold and palladium as an alternative fuel source. Journal Catalysis Letters, v. 128, p. 253-255, 2008.

CARVALHO, P. L. O. et al. Crude glycerine in growing and finishing pigs feeding. Semina: Ciências Agrárias, v. 34, n. 3, p. 1399-1410, 2013.

CERRATE, S. et al. Evaluation of glycerine from biodiesel production as a feed ingredient for broilers. Journal of Poultry Science, v. 5, n. 11, p.1001-1007, 2006.

CHRISTOPHER, S. M. Evaluation of the nutritional value of glycerol, a byproduct of biodiesel production, for swine. 2009. $54 \mathrm{f}$. (Master Animal Science). North Carolina State University, Raleigh, North Carolina.

CONAB. Companhia Nacional de Abastecimento. Acompanhamento da safra brasileira; safra 2015/16. Disponível em: <http://www.conab.gov.br/OlalaCMS/ uploads/arquivos/16_09_09_15_18_32 boletim_12 setembro.pdf $>$ Acesso em: 14 set. 2016.

DOPPENBERG, J.; VAN DER AAR, P. J. Biofuels: Implications for the feed industry. Wageningen Academic Publishers, p. 73-88, 2007.

GALLEGO, A. G. et al. Neutral semi-purified glycerin in starting pigs feeding. Semina: Ciências Agrárias, v. 35, n. 5, p. 2831-2842. 2014.

GONÇALVES L. M. P. et al. Semi purified glycerins in growing and finishing pigs feeding $(30-90 \mathrm{~kg})$. Revista Brasileira de Saúde e Produção Animal, v. 15, n. 1, p. 221-226, 2014

GROESBECK, C. N. et al. Effect of crudeglycerol on pellet mill production and nursery pig growth performance. Journal of Animal Science, v. 86, p. 2228-2236, 2008.
HANCZAKOWSKA, E. et al. Effect of adding crude or refined glycerol to pig diets on fattening performance, nutrient digestibility and carcass evaluation. Annals of Animal Science, v. 10, n. 1, p. 67-73. 2010.

HANSEN, C. F. et al. A chemical analysis of samples of crude glycerol from the production of biodiesel in Australia, and the effects of feeding crude glycerol to growingfinishing pigs on performance, plasma metabolites and meat quality at slaughter. Animal Production Science, v. 49, p. 154-161, 2009.

HUEPA, L. M. D. Glicerina semipurificada neutralizada na alimentação de leitões na fase pré-inicial (6 a 15 kg). (Mestrado em Zootecnia) - Universidade Estadual de Maringá - Maringá PR. 2013.

JAGGER, S. Proceedings of the British Society of Animal Science. In: The implications of biofuel production on intensive livestock production in the United States. Comerford, 1 p. 286-287, 2008.

KERR, B. J. et al. Digestible and metabolizable energy content of crude glycerin originating from different sources in nursery pigs. Journal of Animal Science, v. 87, p. 40424049, 2009.

KERR, B. J. et al. Utilization of crude glycerin in nonruminants. In: Biodiesel- Quality, Emissions and ByProducts, p. 365-380, 2011.

KOJIMA, S. et al. Efficient production of fatty acid methyl ester from waste activated bleaching earth using diesel oil as organic solvent. Journal of Bioscience e Bioengineering, v. 98 , n. 6 , p. 420-424, 2004.

LAMMERS, P. J. et al. Digestible and metabolizable energy of crude glycerol for growing pigs. Journal of Animal Science, v. 86 p. 602-608, 2008a.

LAMMERS, P. J. et al. Growth performance, carcass characteristics, meat quality, and tissuehistology of growing pigs fed crude glycerin supplemented diets. Journal of Animal Science, v. 86, p. 2962-2970, 2008b.

LEONETI,A. B.; LEONETI, V. A.; OLIVEIRA, S. V. W. B. Glycerol as a by-product of biodiesel production in Brazil: Alternatives for the use of unrefined glycerol. Renewable Energy, v. 45, p. 138-145, 2012.

LIN, E. C. C. Glycerol utilization and its regulation in mammals. Annual Review of Biochemistry, v. 46, p. 765 795, 1977.

MELO, D. S. Viabilidade da glicerina bruta na alimentação de suínos em terminação. 2012 (Mestrado em Zootecnia) - Universidade Federal de Lavras - Lavras MG.

MELO, D. S. et al. Qualidade da carne de suínos com uso de glicerina na alimentação. Arquivo Brasileiro de 
Medicina Veterinaria e Zootecnia, v. 66, n. 2, p. 583-592, 2014.

MENDONZA, O. F. et al. Metabolizable energy content of refined glycerin and its effects on growth performance, and carcass and pork quality characteristics of finishing pigs. Journal of Animal Science, v. 88, n. 12, p. 3887-3895, 2010.

MENTEN, J. F. M.; ZAVARIZE, K. C.; SILVA, C. L. S. Biodiesel: oportunidades do uso de glicerina na nutrição de aves. In: IV Congresso Latino Americano de Nutrição Animal, 2010, Estância de São Pedro. Anais... Estância de São Pedro, 2010.

MOUROT, J. et al. Nutritional and physiological effects of dietary glycerol in the growing pig. Consequences on fatty tissues and post mortem muscular parameters. Livestock Production Science, v. 38, p. 237-244, 1994.

OLIVEIRA, J. S. et al. Composição química da glicerina produzida por usinas de biodiesel no Brasil e potencial de uso na alimentação animal. Ciência Rural, v. 43, n. 3, p. 509-512, 2013.

PATIENCE, J. F.; ZIJLSTRA, R. T. Sodium, potassium, chloride, magnesium, and sulfur in swine nutrition. In: Swine Nutrition. 2.ed. Washington, 2001. p.213-227.

RIVALDI, J. D.; SARROUB, B. F.; FIORILO, R.

Glicerol do biodiesel: estratégias biotecnológicas para o aproveitamento do glicerol gerado da produção de biodiesel. Biotecnologia, Ciência e Desenvolvimento, n. 37, p. 4451, 2008.

ROCHA, L. O. Glicerina bruta na alimentação de suínos nas fases pré inicial e inicial. 2013 (Doutorado em Ciência Animal) - Universidade Federal de Goiás - Goiânia.

ROSTAGNO, H. S. et al. Tabelas brasileiras para aves e suínos: composição de alimentos e exigências nutricionais. 2.ed. Viçosa: Universidade Federal de Viçosa, 2011. 252p.

SCHIECK, S. et al. Evaluation of glycerol, a biodiesel coproduct, in grow-finish pig diets to support growth and improve pork quality. In: University of Minnesota final report to Minnesota Pork Board. 2009

SILVA, C. L. S. Glicerina proveniente da produção de biodiesel como ingrediente de ração para frangos de corte. 2010 (Mestrado em Ciência Animal e Pastagens) - Escola Superior de Agricultura "Luis de Queiroz". Universidade de São Paulo. Piracicaba.

THOMPSON, J. C.; HE, B. Characterization of crude glycerol from biodiesel production from multiple feedstocks. Applied Engineering in Agriculture, v. 22, n. 2, p. 261-265, 2006.

VAN HEUGTEN, E. et al. Evaluation of the nutritional value of glycerol, a byproduct of biodiesel production, for swine. In: North Carolina pork council. 2008.

ZIJLSTRA, R. T. et al. The effect of feeding crude glycerol on growth performance and nutrient digestibility in weaned pigs. Journal of Animal Science, v. 89, n. 1, p.85-89, 2009.

Recebido em: 28.08.2015 Aceito em: 26.11.2016 